\title{
Predictive value of the age, creatinine and ejection fraction score in patients undergoing primary percutaneous coronary intervention with bail-out tirofiban therapy
}

\author{
Altuğ Ösken ${ }^{1}$, Recep Haci ${ }^{1,2}$, Sena Sert Şekerci ${ }^{1}$, Lale Dinç Asarcıklı1 ${ }^{1}$, Gizem Yüksel ${ }^{1}$, Büşra Ceylan ${ }^{1}$, \\ Şennur Ünal Dayı ${ }^{1}$, Neşe Çam ${ }^{1}$ \\ ${ }^{1}$ Department of Cardiology, Dr. Siyami Ersek Thoracic and Cardiovascular Surgery Center, Training and Research Hospital, Istanbul, Turkey \\ ${ }^{2}$ Department of Cardiology, Yalova State Hospital, Yalova, Turkey
}

Adv Interv Cardiol 2021; 17, 2 (64): 170-178 DOI: https://doi.org/10.5114/aic.2021.107495

\begin{abstract}
Introduction: In patients who have undergone interventional cardiac procedures, the risk of bleeding is higher than in patients who received conservative treatment due to multiple medications and comorbidities.

Aim: This study aimed to evaluate the usefulness of the age, creatinine and ejection fraction (ACEF) score for predicting bleeding events and to compare short- and long-term clinical outcomes according to the ACEF score in patients with ST-elevation myocardial infarction (STEMI) undergoing primary percutaneous coronary intervention (pPCI) with bail-out tirofiban therapy (BOTT).

Material and methods: A total of 2,543 patients were included and divided into three groups according to the following ACEF score tertiles: $\mathrm{T} 1\left(\mathrm{ACEF}_{\text {low }} \leq 1.033\right), \mathrm{T} 2\left(1.033<\mathrm{ACEF}_{\text {mid }} \leq 1.371\right)$, and $\mathrm{T} 3\left(\mathrm{ACEF}_{\text {high }}>1.371\right)$. The main outcomes measured were the incidence rates of relevant bleeding events and mortality within 30 days and 3 years after the procedure.

Results: A total of 73 (2.9\%) patients had Bleeding Academic Research Consortium bleeding events of grades 3, 4 or 5 and 104 (4\%) patients died in a 30-day period. The ACEF score was effective at predicting 30-day bleeding (area under the receiver operating characteristic curve (AUC): $0.658,95 \%$ confidence interval (CI): 0.579-0.737; $p<0.001$ ), 30-day mortality (AUC $=0.701,95 \% \mathrm{Cl}$ : $0.649-0.753 ; p<0.001$ ) and 3-year mortality (AUC $=0.778,95 \% \mathrm{Cl}: 0.748-0.807 ; p<0.001)$ events. Considering the ACEF score tertiles, $\mathrm{T} 3$ patients presented greater 30 -day bleeding (1.6\%, $2.8 \%$ and $4.1 \%$; odds ratio $(\mathrm{OR})=2.56,95 \% \mathrm{Cl}: 1.37-4.80)$, 30 -day mortality $(1.7 \%, 3.5 \%$ and $7.1 \%$; $\mathrm{OR}=4.53,95 \% \mathrm{Cl}: 2.51-8.18)$ and 3 -year mortality $(6.4 \%, 11 \%$ and $19.8 \%$; hazard ratio $=3.56$, $95 \% \mathrm{Cl}: 2.58-4.91)$ risks.

Conclusions: The ACEF score is a user-friendly tool with excellent predictive value for bleeding events and mortality in patients undergoing $\mathrm{PPCl}$ with BOTT.
\end{abstract}

Key words: acute ST-segment elevation myocardial infarction, ACEF score, primary percutaneous coronary intervention.

Su m m a ry

Prediction of mortality and major adverse cardiac/cerebral events with the age, creatinine and ejection fraction (ACEF) score has been previously presented in the literature. The predictive value of this scoring for bleeding events has not yet been studied. Our study aimed to investigate the predictive value of the ACEF score for bleeding and mortality events in ST-elevation myocardial infarction patients treated with bail-out tirofiban therapy. Since the ACEF score can be calculated easily and can be applied to routine practice, it would be rational to use it in this patient group.

\section{Introduction}

ST-segment-elevation myocardial infarction (MI) (STEMI) patients remain at high risk for major adverse cardiac, cerebral and hemorrhagic events despite optimal medical therapy and successful primary percutaneous coronary intervention $(\mathrm{PCl})(\mathrm{pPCl})[1]$. According to current

\section{Corresponding author:}

Altuğ Ösken, Department of Cardiology, Dr. Siyami Ersek Thoracic and Cardiovascular Surgery Center, Training and Research Hospital, 13 Tibbiye St, Haydarpasa, Istanbul, Turkey, phone: 0216-5424444, fax: 0216-4596321, e-mail: alosk@hotmail.com

Received: 11.03.2021, accepted: 20.04.2021. 
guideline recommendations, it is necessary to use dual antiplatelets for at least 1 year in the treatment of acute coronary syndromes (ACS) [2]. Although these medications are known to reduce ischemic events, there is strong evidence that there is a significant relationship between dual antiplatelet use and increased bleeding complications and mortality [3].

In patients with ACS, numerous bleeding risk-stratification scores have been developed with differing advantages or disadvantages [4, 5]. Although the age, creatinine, and ejection fraction (ACEF) score was first developed to predict mortality in elective coronary artery bypass graft (CABG) operations [6], whether it could be a predictor of bleeding events in conservatively treated patients has also been discussed in the literature [7]. Tirofiban is a glycoprotein IIb/IIla inhibitor and recommended as a bail-out therapy in STEMI patients [8]. A significant decrease in the frequency of adverse cardiac events after the use of tirofiban in addition to heparin has been observed in patients with ACS, while the frequency of bleeding events does not increase $[9,10]$.

\section{Aim}

We conducted the present study based on the hypothesis that the ACEF score would therefore be able to predict Bleeding Academic Research Consortium (BARC) bleeding events of grade 3,4 , or 5 and mortality in STEMI patients undergoing pPCI with bail-out tirofiban therapy (BOTT).

\section{Material and methods}

\section{Study design}

This was a retrospective observational study conducted at Dr. Siyami Ersek Thoracic and Cardiovascular Centre between January 2012 and December 2016 of patients who underwent $\mathrm{PPCl}$ with BOTT following a diagnosis of STEMI. It was approved by the Haydarpasa Numune Education and Research Hospital ethics committee (approval no. 2021/81) and carried out following the principles of the Declaration of Helsinki. Written informed consent was obtained from the patients during their hospitalization.

\section{Study population}

The medical records of 5,749 consecutive STEMI patients undergoing $\mathrm{PPCl}$ were scanned and 2,744 patients who received BOTT were selected for inclusion in this study. Patients with a life expectancy of less than 1 year due to severe concomitant noncardiac disease (e.g., tumor, infection), those with missing data for ACEF score calculation, and those lost to follow-up were excluded from the study. Finally, a total of 2,543 patients were enrolled for analysis (Figure 1 ).

\section{Data collection}

Demographic, clinical, laboratory, and angiographic characteristics of study participants were obtained from the hospital database. The left ventricular ejection fraction (LVEF) was calculated according to guideline recommendations by a blinded echocardiographer using the standard biplane Simpson method. pPCI operations were carried out per the guideline recommendations and the types of interventions applied during the procedure were chosen according to the operator's discretion.

After hospital discharge, all patients were instructed to use dual antiplatelet therapy for at least 1 year and were followed up at outpatient clinics regarding any adverse cardiac or bleeding events after discharge. Any such events they experienced were accessed via the social security institution database and, when necessary, the patients were contacted by phone and additional information about their clinical status was obtained.

\section{Definitions}

The ACEF score was calculated according to the following previously defined formula [6]: age/left ventricular ejection fraction + 1 (if creatinine was > $2 \mathrm{mg} / \mathrm{dl}$ ). Then, patients were stratified into three tertiles based on their ACEF scores.

Anemia was defined using the World Health Organization definition: hemoglobin $<12 \mathrm{~g} / \mathrm{dl}$ for women and $<13 \mathrm{~g} / \mathrm{dl}$ for men [11].

BARC bleeding events of grade 3,4 , or 5 (BARC 3-5) during a 30-day period were analyzed according to the following definitions: BARC 3a: overt bleeding plus hemoglobin drop of 3 to $<5 \mathrm{~g} / \mathrm{dl}$ (provided hemoglobin drop is related to bleeding); transfusion with overt bleeding, BARC $3 \mathrm{~b}$ : overt bleeding plus hemoglobin drop $\geq 5 \mathrm{~g} / \mathrm{dl}$ (provided hemoglobin drop is related to bleeding); cardiac tamponade; bleeding requiring surgical intervention for control; bleeding requiring IV vasoactive agents,

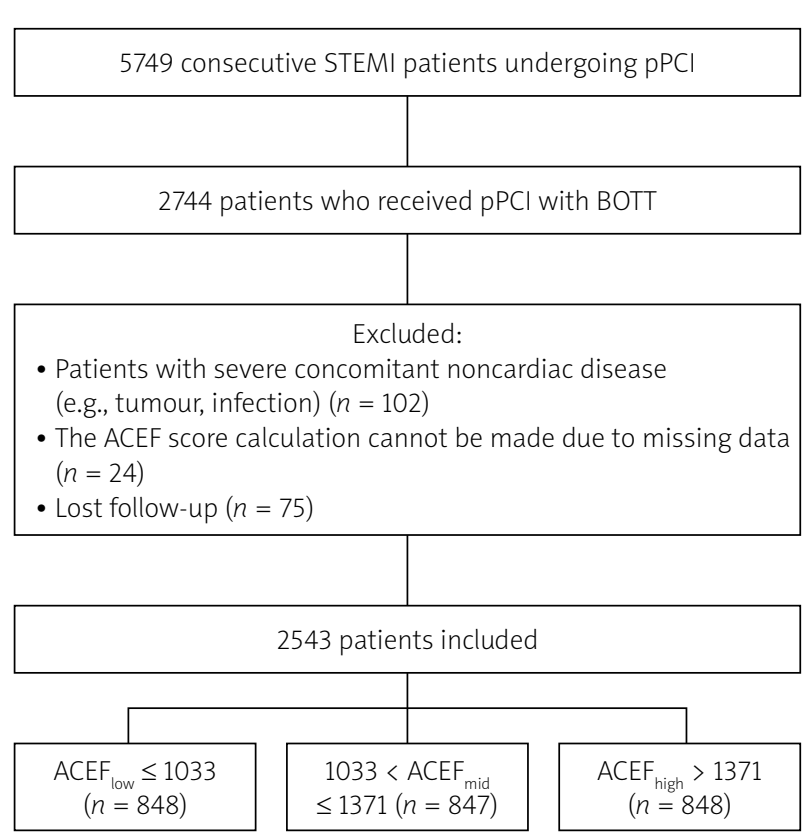

Figure 1. Flow chart 
BARC 3c: intracranial hemorrhage confirmed by autopsy, imaging, or lumbar puncture; intraocular bleed compromising vision, BARC 4: CABG-related bleeding within $48 \mathrm{~h}$, BARC 5a: probable fatal bleeding, BARC 5b: definite fatal bleeding (overt or autopsy or imaging confirmation) [12].

\section{Endpoints}

The primary endpoint of this study was BARC 3-5 events or mortality within 30 days after $\mathrm{pPCl}$. The secondary endpoint included long-term all-cause mortality.

\section{Statistical analysis}

All analyses were conducted using the program SPSS Statistics version 22.0 (IBM Corporation, Armonk, NY, USA). After deploying the Kolmogorov-Smirnov normality test for data, continuous variables were represented as mean \pm standard deviation or median (interquartile range) values. Those variables with normal distribution were tested with a one-way analysis of variance, while if the variables were nonparametric, they were assessed with the Kruskal-Wallis test. Categorical variables were represented as number (percentage) and were assessed using the chi-squared or Fisher's exact test.

Multinomial logistic regression analysis and Cox proportional hazards modeling were used to compare shortand long-term mortality between the tertiles. Binary logistic regression analysis was performed to evaluate the predictors of bleeding events. Receiver operating characteristic (ROC) curves were constructed to assess the ability of the ACEF score to predict events. The long-term survival was generated by the Kaplan-Meier method, and the log-rank test was used to evaluate differences between the groups.

\section{Results}

The study population included 2,543 patients, who were stratified according to the ACEF score tertiles as follows: 848 patients in $\mathrm{T} 1\left(\mathrm{ACEF}_{\text {low }} \leq 1.033\right), 847$ patients in $\mathrm{T} 2\left(1.033<\mathrm{ACEF}_{\text {mid }} \leq 1.371\right)$, and 848 patients in T3 $\left(\mathrm{ACEF}_{\text {high }}>1.371\right)$. Baseline clinical, demographic, and angiographic characteristics of the study participants are listed in Table I. In patients with higher ACEF scores (T3), age and basal creatinine values were already high; additionally, patients in the T3 group were more likely to have diabetes mellitus, hypertension, and a prior history of MI, $\mathrm{PCl}$, and $\mathrm{CABG}$. The highest number of patients presenting with anterior $\mathrm{MI}$ was in T3. While multivessel disease was common in the T3 group, most of the patients in the $\mathrm{T} 1$ group had single-vessel disease. After the $\mathrm{pPCl}$ procedure, Thrombolysis in Myocardial Infarction grade III flow was the lowest in the T3 group.

Upon examining the causes of BARC $3-5$ events $(n=73)$, most were the result of femoral vascular access-site complications ( $n=34 ; 47 \%)$, while others included upper gastrointestinal bleeding ( $n=20 ; 27 \%)$, lower gastroin- testinal bleeding ( $n=8 ; 11 \%)$, urinary system bleeding $(n=5 ; 7 \%)$, retroperitoneal hematoma $(n=4 ; 5 \%)$ and intracranial hemorrhage ( $n=2 ; 2 \%)$ (Figure 2 ).

The ACEF score significantly predicted the rates of BARC $3-5$ events and mortality within 30 days as well as the rate of all-cause mortality at 3 years. In-hospital and 30-day BARC 3-5 events occurred more frequently in $\mathrm{T} 3$ patients $(1.6 \%, 2.8 \%$, and $4.1 \%$, respectively). Further, 30-day and 3-year mortality rates were also higher in the T3 group $(1.7 \%, 3.5 \%$, and $7.1 \%$ vs $6.4 \%, 11 \%$, and $19.8 \%$, respectively). Table II lists unadjusted and adjusted multinomial logistic regression and Cox proportional hazard analysis results for BARC 3-5 events and mortality rates. T3 patients were 2.56 times more likely to experience BARC $3-5$ events (95\% confidence interval (Cl): 1.37-4.80) than T1 patients, who were considered as the reference group. Also, the highest 30-day and 3-year mortality rates were found among patients in T3 with 4.53-fold higher 30-day mortality $(95 \% \mathrm{Cl}$ : 2.51-8.18) and 3.56-fold higher 3-year mortality $(95 \% \mathrm{Cl}$ : 2.58-4.91) rates than patients in T1. These significant relationships persisted even after making adjustments for all confounders.

To evaluate the parameters that predict BARC 3-5 events across the entire study population, we performed a logistic regression analysis. History of $\mathrm{MI}$, diastolic blood pressure, admission anemia, and ACEF score were deemed to be independent predictors of BARC 3-5 events in the univariate analysis. During the stepwise backward logistic regression analysis, when using a model adjusted for the aforementioned parameters, admission anemia $(\mathrm{OR}=1.176,95 \% \mathrm{Cl}: 1.079-2.037 ; p=0.043)$ and $\mathrm{ACEF}$ score $(\mathrm{OR}=3.903,95 \% \mathrm{Cl}: 2.806-5.326 ; p<0.001)$ were independently associated with BARC 3-5 events (Table III).

In the ROC analysis, the area under the ROC curve (AUC) values of the ACEF score for 30-day BARC 3-5 events and 30-day and 3-year mortality rates were 0.658 (95\% Cl: 0.579-0.737), 0.701 (95\% Cl: 0.649-0.753) and 0.778 (95\% Cl: 0.748-0.807), respectively (Figures 3-5). Additionally, the 3-year Kaplan-Meier overall survival rates for $\mathrm{T} 1, \mathrm{~T} 2$, and $\mathrm{T} 3$ were $93.6 \%, 89 \%$, and $80.2 \%$, respectively (Figure 6).

\section{Discussion}

The current study analyzed the prognostic implications of the ACEF score and compared 30-day bleeding and mortality events and 3-year mortality events among STEMI patients undergoing $\mathrm{PPCl}$ in conjunction with BOTT. The principal finding was as follows: bleeding and mortality events were more common in patients with higher ACEF score tertiles. Patients with higher ACEF scores were older and more fragile with impaired left ventricular systolic function, so more bleeding and mortality events are to be expected in this population. Among STEMI patients, non-life-threatening minor hem- 
Table I. Baseline characteristics of patients categorized according to ACEF score tertiles

\begin{tabular}{|c|c|c|c|c|}
\hline Parameter & $\begin{array}{c}\text { ACEF }(<1.033) \\
(n=848)\end{array}$ & $\begin{array}{c}\text { ACEF }(1.033-1.371) \\
(n=847)\end{array}$ & $\begin{array}{c}\text { ACEF }(>1.371) \\
(n=848) \\
\end{array}$ & $P$-value \\
\hline \multicolumn{5}{|l|}{ Characteristics: } \\
\hline Age [years] mean & $48.6 \pm 7.5$ & $58.9 \pm 8.3$ & $65.5 \pm 10.2$ & $<0.001$ \\
\hline BMI & 40 (29.6) & $57(42.2)$ & $42(31.1)$ & $<0.001$ \\
\hline Gender, male & $747(88.1)$ & $722(85.2)$ & $647(76.3)$ & $<0.001$ \\
\hline Hypertension & $171(20.2)$ & $225(26.6)$ & $259(30.5)$ & $<0.001$ \\
\hline Diabetes mellitus & $116(13.8)$ & $175(20.9)$ & $212(25.3)$ & $<0.001$ \\
\hline Hyperlipidemia & $161(19)$ & $140(16.5)$ & $160(18.9)$ & 0.334 \\
\hline Current smoking & $304(35.8)$ & $227(26.8)$ & $191(22.5)$ & $<0.001$ \\
\hline Previous myocardial infarction & $163(19.2)$ & $250(29.5)$ & $259(30.5)$ & $<0.001$ \\
\hline Previous percutaneous coronary intervention & $172(20.3)$ & $237(28)$ & $267(31.5)$ & $<0.001$ \\
\hline Previous coronary artery bypass graft surgery & $15(1.8)$ & $57(6.7)$ & $82(9.7)$ & $<0.001$ \\
\hline Ejection fraction & $56 \pm 6$ & $50.1 \pm 7.2$ & $37.4 \pm 8.9$ & $<0.001$ \\
\hline Anterior myocardial infarction & $343(40.4)$ & $307(36.2)$ & $431(50.8)$ & $<0.001$ \\
\hline Blood pressure (systolic) & $134.9 \pm 22$ & $135.1 \pm 22.9$ & $133 \pm 26.2$ & 0.146 \\
\hline Blood pressure (diastolic) & $71.3 \pm 12.2$ & $71.2 \pm 12$ & $75(55.6)$ & 0.160 \\
\hline Heart rate & $77.8 \pm 13.2$ & $78.2 \pm 14.6$ & $70.3 \pm 13.9$ & 0.586 \\
\hline Door to balloon time & $19.9 \pm 9.8$ & $19.8 \pm 10$ & $20.2 \pm 9.8$ & 0.739 \\
\hline Symptom onset & $7.3 \pm 5.8$ & $7.7 \pm 6$ & $7.5 \pm 6$ & 0.303 \\
\hline Killip classification $\geq 2$ & $203(23.9)$ & $207(24.4)$ & $216(25.4)$ & 0.215 \\
\hline \multicolumn{5}{|l|}{ Infarct related artery: } \\
\hline Left main & $1(0.1)$ & $3(0.4)$ & $4(0.5)$ & 0.533 \\
\hline Left anterior descending & $390(46)$ & $347(41)$ & $465(54.8)$ & $<0.001$ \\
\hline Left circumflex & $129(15.2)$ & $123(14.5)$ & $127(12.6)$ & 0.283 \\
\hline Right coronary artery & $327(38.6)$ & $352(41.6)$ & $244(28.8)$ & $<0.001$ \\
\hline Saphenous graft & $2(0.2)$ & $25(3)$ & $31(3.7)$ & $<0.001$ \\
\hline \multicolumn{5}{|l|}{ Vessel stenosis (> 50\%): } \\
\hline 1 vessel & $558(65.8)$ & $476(56.2)$ & $457(53.9)$ & $<0.001$ \\
\hline 2 vessels & $197(23.2)$ & $212(25)$ & $203(23.9)$ & 0.683 \\
\hline 3 vessels & $93(11)$ & $159(18.8)$ & $187(22.1)$ & $<0.001$ \\
\hline \multicolumn{5}{|l|}{ TIMI flow after intervention: } \\
\hline TIMI 0 & $45(5.3)$ & $49(5.8)$ & $57(6.7)$ & 0.455 \\
\hline TIMI I & $63(7.4)$ & $72(8.5)$ & $72(8.5)$ & 0.651 \\
\hline TIMI II & $66(7.8)$ & $81(9.6)$ & $94(11.1)$ & 0.067 \\
\hline TIMI III & $674(79.5)$ & $645(76.2)$ & $626(73.8)$ & 0.022 \\
\hline \multicolumn{5}{|l|}{ Angiographic and procedural characteristics: } \\
\hline Stent diameter & $3(3-3.5)$ & $3(2.75-3.5)$ & $3(2.75-3.5)$ & 0.018 \\
\hline Stent length & $20(16-25)$ & $20(16-25)$ & $20(16-25)$ & 0.562 \\
\hline POBA & $109(12.9)$ & $131(15.5)$ & $166(19.6)$ & $<0.001$ \\
\hline Direct stenting & $156(18.4)$ & $117(13.8)$ & $86(10.1)$ & $<0.001$ \\
\hline PTCA and stenting & $541(63.8)$ & $571(67.4)$ & $565(66.6)$ & 0.255 \\
\hline Thrombus aspiration & $69(8.1)$ & $61(7.2)$ & $73(86)$ & 0.554 \\
\hline Drug eluting stent & $532(62.7)$ & $540(63.8)$ & $515(60.7)$ & 0.425 \\
\hline Bare metal stent & $106(12.5)$ & $100(11.8)$ & $94(11.1)$ & 0.665 \\
\hline Follow-up time & $34.9 \pm 5.7$ & $33.8 \pm 7.8$ & $29.4 \pm 12.1$ & $<0.001$ \\
\hline \multicolumn{5}{|l|}{ Medication at discharge: } \\
\hline Statin & $767(90.4)$ & $742(87.6)$ & 747 (88) & 0.523 \\
\hline ACE-I/ARB & 813 (95.8) & 794 (93.7) & 789 (93.0) & 0.175 \\
\hline$\beta$-Blocker & 761 (89.7) & $749(88.4)$ & $741(87.4)$ & 0.444 \\
\hline
\end{tabular}


Table I. Cont.

\begin{tabular}{lcccc} 
Parameter & ACEF $(<1.033)$ \\
$(n=848)$ & ACEF $(1.033-1.371)$ & ACEF $(>1.371)$ & $P$-value \\
$(n=847)$ & & & & \\
\hline Admission laboratory parameters: & & $154.1 \pm 74.4$ & $170.4 \pm 90.9$ & $<0.001$ \\
\hline Glucose $[\mathrm{mg} / \mathrm{dl}]$ & $138 \pm 57.9$ & $0.9 \pm 0.24$ & $1.03 \pm 0.65$ & $<0.001$ \\
\hline Baseline creatinine $[\mathrm{mg} / \mathrm{dl}]$ & $0.84 \pm 0.18$ & $107.8 \pm 34.8$ & $94 \pm 40.2$ & $<0.001$ \\
\hline eGFR $[\mathrm{ml} / \mathrm{min}]$ & $127.3 \pm 39.6$ & $171(20.4)$ & $221(26.1)$ & $<0.001$ \\
\hline Admission anemia & $110(12.9)$ & $11.71 \pm 5.83$ & $12.09 \pm 4.74$ & 0.280 \\
\hline Leukocyte $\left[\times 10^{9} / \mathrm{ll}\right]$ & $11.93 \pm 3.92$ & $13.83 \pm 1.67$ & $14.1 \pm 1.8$ & $<0.001$ \\
\hline Red cell distribution width $(\%)$ & $13.61 \pm 1.48$ & $8.78 \pm 1.09$ & $8.95 \pm 1.12$ & $<0.001$ \\
\hline MPV $[\mathrm{fl}]$ & $8.69 \pm 1.05$ & $245.7 \pm 69.6$ & $247 \pm 79$ & 0.140 \\
\hline Platelet $\left[\times 10^{9} / \mathrm{l}\right]$ & $252.6 \pm 78.7$ & $1.18 \pm 0.09$ & $1.87 \pm 0.51$ & $<0.001$
\end{tabular}

$A C E-I$ - angiotensin converting enzyme inhibitor, $A R B$ - angiotensin receptor blocker, BMI-body mass index, LVEF-left ventricle ejection fraction, POBA - plain old balloon angioplasty, PTCA - percutaneous transluminal coronary angioplasty, GFR-glomerular filtration rate, RDW-red cell distribution width, MPV - mean platelet volume, ACEF-age - left ventricular ejection fraction and creatinine.

orrhages are common, and rare instances of major hemorrhage can occur. The use of the BARC classification scheme seems rational in these patients [13].

Since the risk of recurrent ischemic events after $\mathrm{PCl}$ is higher in patients with an ACS diagnosis, a period of at least 12 months of dual antiplatelet therapy is required. During invasive procedures, some patients may develop iatrogenic coronary artery dissection, angiographic no-reflow phenomenon, or distal embolization, and these patients may need to be given bail-out glycoprotein Ilb/ Illa inhibitors along with unfractionated heparin therapy [14]. With the concomitant use of these medications, an increase in the frequency of bleeding events can be seen in the hospital period [15]. Although clinical studies [16-21] have reported that tirofiban therapy may facilitate minor bleeding, it has been reported that no significant increase in major bleeding events occurs even when this drug is used concomitantly with other medications. Since we specifically included STEMI patients treated with tirofiban in our study, we could not predict whether the ACEF score can predict bleeding events as compared to patients without tirofiban therapy.

Current guidelines recommend the use of bleeding risk scores in patients with ACS to predict in-hospital bleeding events [22]. Vascular access site complications are the most common cause of in-hospital bleeding. However, gastrointestinal system, urinary, and, rarely, intracranial bleeding may occur [23]. Bleeding risk scores are specifically designed to determine the in-hospital risk level, so they may be insufficient to predict long-term bleeding events [24]. Following the existing literature, we observed that bleeding most frequently resulted from vascular access-site complications and we wanted to investigate only those bleeding events in the first 30 days instead of in the long term.

Multiple risk-prediction models have been proposed for predicting post-MI bleeding and mortality outcomes, including clinical, angiographic, or combined scoring systems [25-27]. The ACEF score was first developed to predict the endpoints of patients undergoing bypass surgery [6]. Afterward, different models were created for patients with ACS by combining the ACEF score with various clinical and angiographic variables, which enhanced the power of this scoring scheme to predict outcomes [28-31]. On the other hand, in a recent study by Kristic et al. with NSTEMI patients, the ACEF score showed better discrimination than the other six clinical, angiographic, or combined risk scores [32].

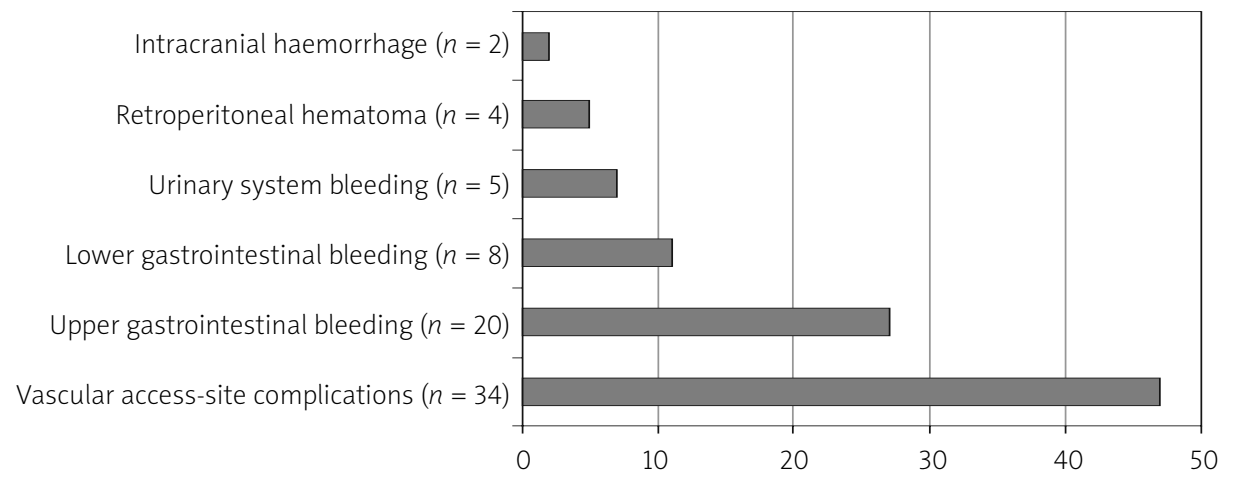

Figure 2. Causes of BARC $3-5$ events in the study population 
Table II. Unadjusted and multivariable regression analysis for 30-day BARC 3-5 bleeding events - mortality and 3-year mortality stratified by ACEF score tertiles

\begin{tabular}{|c|c|c|c|}
\hline Variable & $\begin{array}{c}\text { ACEF }(<1.033) \\
(n=848)\end{array}$ & $\begin{array}{c}\text { ACEF }(1.033-1.371) \\
(n=847)\end{array}$ & $\begin{array}{c}\text { ACEF }(>1.371) \\
(n=848)\end{array}$ \\
\hline \multicolumn{4}{|l|}{ BARC 3-5 bleeding (30-day): } \\
\hline Number of events & 14 & 24 & 35 \\
\hline Events (\%) & 1.6 & 2.8 & 4.1 \\
\hline \multicolumn{4}{|l|}{ Event, OR (\%95 CI): } \\
\hline Model 1: unadjusted & $1[$ Reference $]$ & $1.49(0.87-2.50)$ & $2.56(1.37-4.80)$ \\
\hline Model 2: adjusted for age and sex & $1[$ Reference] & $1.21(0.69-2.13)$ & $1.49(0.68-3.29)$ \\
\hline Model 3: adjusted for comorbidities & $1[$ Reference $]$ & $1.48(0.87-2.52)$ & $2.34(1.23-4.46)$ \\
\hline Model 4: adjusted for all covariates ${ }^{a}$ & $1[$ Reference $]$ & $1.25(0.64-2.49)$ & $1.59(0.73-3.50)$ \\
\hline \multicolumn{4}{|l|}{ 30-day mortality: } \\
\hline Number of deaths & 14 & 30 & 60 \\
\hline Mortality (\%) & 1.7 & 3.5 & 7.1 \\
\hline \multicolumn{4}{|l|}{ Mortality, OR (\%95 Cl): } \\
\hline Model 1: unadjusted & $1[$ Reference $]$ & $2.07(1.32-3.24)$ & $4.53(2.51-8.18)$ \\
\hline Model 2: adjusted for age and sex & $1[$ Reference $]$ & $1.74(1.08-2.8)$ & $3.06(1.51-6.2)$ \\
\hline Model 3: adjusted for comorbidities & $1[$ Reference $]$ & $2.09(1.37-3.30)$ & $4.17(2.29-7.6)$ \\
\hline Model 4: adjusted for all covariates ${ }^{a}$ & $1[$ Reference $]$ & $1.36(0.73-2.43)$ & $2.43(1.15-5.23)$ \\
\hline \multicolumn{4}{|l|}{ 3-year mortality: } \\
\hline Number of deaths & 55 & 92 & 168 \\
\hline Mortality (\%) & 6.4 & 11 & 19.8 \\
\hline \multicolumn{4}{|l|}{ Mortality, HR (\%95 Cl): } \\
\hline Model 1: unadjusted & $1[$ Reference $]$ & $2.02(1.54-2.66)$ & $3.56(2.58-4.91)$ \\
\hline Model 2: adjusted for age and sex & $1[$ Reference $]$ & $1.58(1.18-2.12)$ & $1.91(1.28-2.86)$ \\
\hline Model 3: adjusted for comorbidities & $1[$ Reference $]$ & $2.01(1.52-2.66)$ & $3.50(2.51-4.87)$ \\
\hline Model 4: adjusted for all covariates ${ }^{a}$ & $1[$ Reference $]$ & $1.69(1.25-2.27)$ & $2.51(1.77-3.51)$ \\
\hline
\end{tabular}

Table III. Univariate analysis and multivariate model for prediction of BARC 3-5 bleeding events in the entire study population

\begin{tabular}{|c|c|c|c|c|c|}
\hline Univariate analysis & $P$-value & OR $(95 \% \mathrm{Cl})$ & Multivariate analysis & $P$-value & OR $(95 \% \mathrm{Cl})$ \\
\hline Male gender & 0.690 & $1.142(0.596-2.186)$ & & & \\
\hline Body mass index & 0.818 & $1.007(0.949-1.068)$ & & & \\
\hline Hypertension & 0.551 & $1.169(0.699-1.957)$ & & & \\
\hline Diabetes mellitus & 0.477 & $1.222(0.704-2.121)$ & & & \\
\hline Hyperlipidemia & 0.196 & $0.628(0.310-1.271)$ & & & \\
\hline Current smoking & 0.473 & $0.821(0.479-1.408)$ & & & \\
\hline History of myocardial infarction & 0.040 & $1.661(1.024-2.694)$ & & & \\
\hline Blood pressure (diastolic) & 0.018 & $0.971(0.953-0.987)$ & & & \\
\hline Glucose [mg/dl] & 0.185 & $1.002(0.999-1.004)$ & & & \\
\hline Admission anemia & 0.012 & $1.912(1.155-3.164)$ & Admission anemia & 0.043 & $1.176(1.079-2.037)$ \\
\hline Leukocytes $\left[\times 10^{9} / I\right]$ & 0.818 & $1.005(0.961-1.051)$ & & & \\
\hline ACEF score & $<0.001$ & $3.988(2.947-5.397)$ & ACEF score & $<0.001$ & $3.903(2.860-5.326)$ \\
\hline
\end{tabular}

ACEF - age, creatinine and ejection fraction, BARC - Bleeding Academic Research Consortium, OR - odds ratio, Cl-confidence interval. 


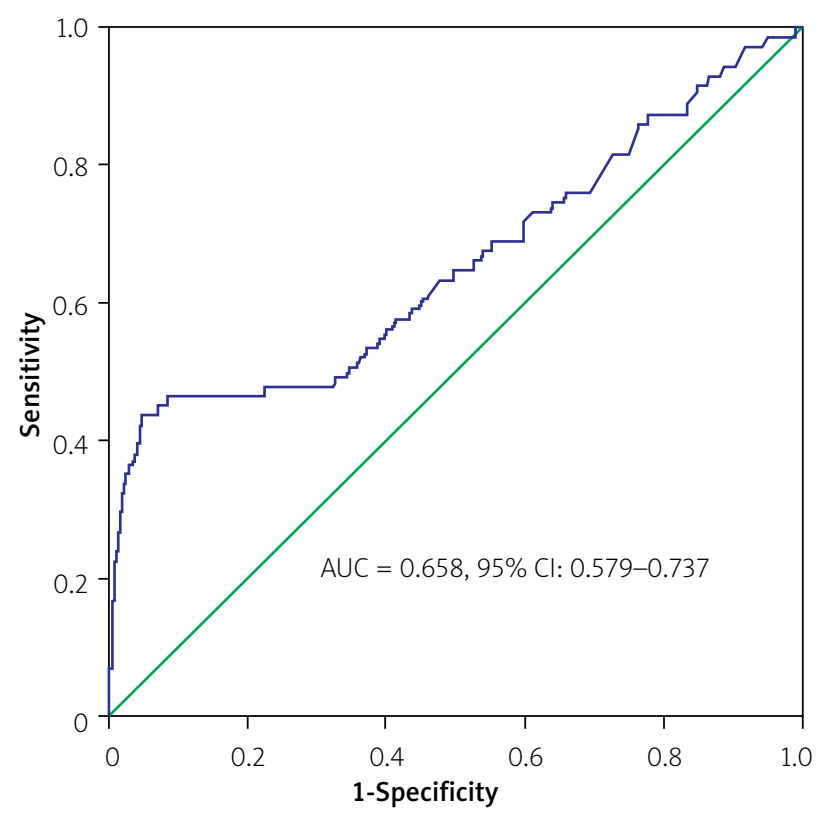

Figure 3. Receiver operating characteristic (ROC) curves of ACEF score and 30-day BARC 3-5 events

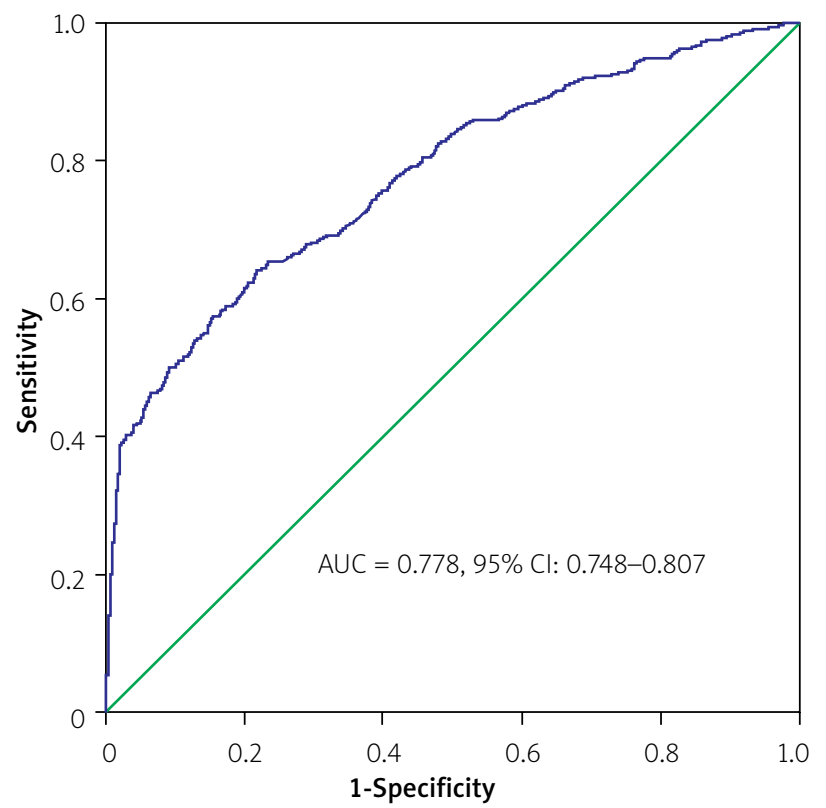

Figure 5. Receiver operating characteristic (ROC) curves of ACEF score and 3-year mortality

In our study population, the prevalence of anemia at admission was significantly higher in those with high ACEF scores. Anemia has an established adverse prognostic value in the setting of ACS [33]. Vrsalovic et al. found that the presence of anemia at admission is an independent predictor of 30-day mortality in STEMI patients [34]. When we investigated the BARC 3-5 event development by including the entire patient population, we also found that admission anemia and ACEF score were independent predictors. Moghaddam et al. did not observe a significant increase in all-cause mortality

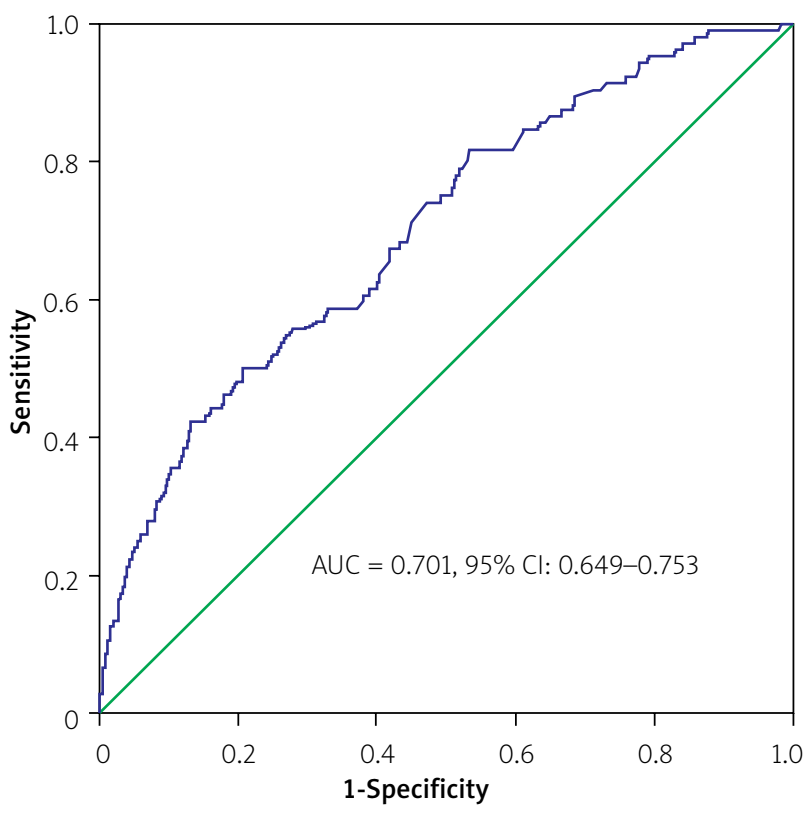

Figure 4. Receiver operating characteristic (ROC) curves of ACEF score and 30-day mortality

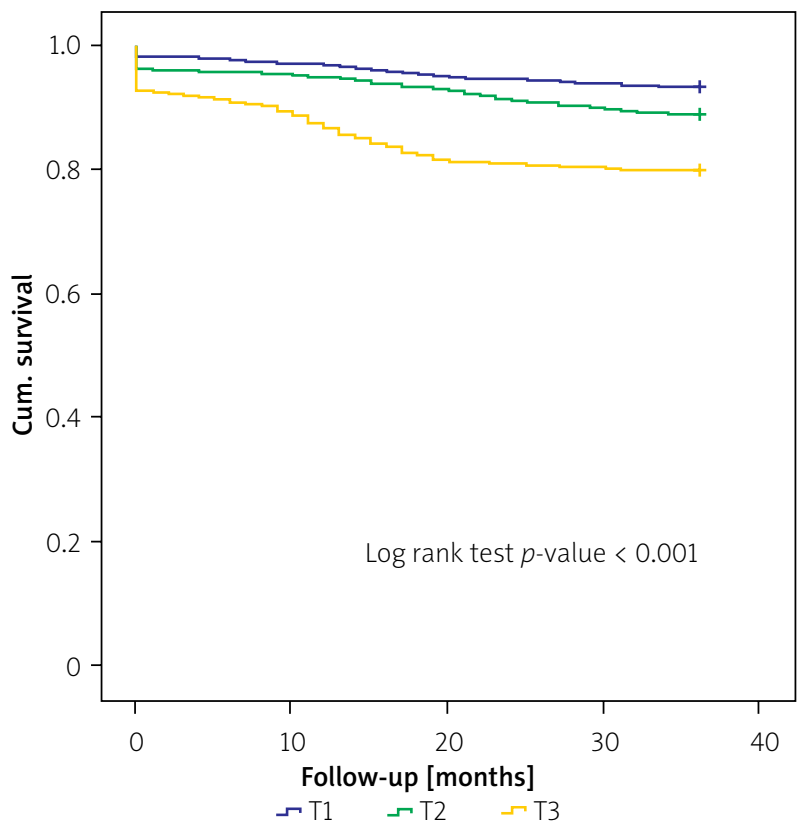

Figure 6. Kaplan-Meier survival curve for overall survival in study population stratified by ACEF score tertiles. The 3-year Kaplan-Meier overall survival rates for T1, T2 and T3 were 93.6\%, 89\% and $80.2 \%$ respectively

in STEMI patients with anemia at admission but found a significant relationship with major bleeding [35].

However, although the predictive power of the ACEF and modified ACEF scores in STEMI patients has been proven, no clinical study in the literature has yet evaluated both bleeding and mortality events in patients undergoing $\mathrm{PPCl}$ with concomitant BOTT. Based on the 
main findings of our study, we concluded that the ACEF score, which is a practical and easily calculable score, in addition to predicting mortality, can also be a powerful predictor of bleeding events, so we think that our study contributes to the literature in this respect.

This was a retrospective observational study conducted at a single center and, as such, has the inherent limitations of this kind of study design. In the study population, we did not adopt bleeding risk-scoring systems that included clinic and angiographic variables. Addition of these scales to the ACEF score may have resulted in a clinically meaningful improvement in the prediction of bleeding events. Also, we were only able to analyze BARC 3-5 events within 30 days in this study, and our analysis of bleeding events occurring within the 3-year follow-up period may further contribute to the literature.

\section{Conclusions}

Bleeding and mortality events are more common among patients with higher ACEF scores. The ACEF score, which can be calculated easily and has significant power for predicting clinical events, seems rational to apply to STEMI patients in whom tirofiban is administered together with other drugs.

\section{Conflict of interest}

The authors declare no conflict of interest.

\section{References}

1. Levine GN, Bates ER, Blankenship JC, et al. 2015 ACC/AHA/SCAl focused update on primary percutaneous coronary intervention for patients with st-elevation myocardial infarction: an update of the 2011 ACCF/AHA/SCAI Guideline for percutaneous coronary intervention and the 2013 ACCF/AHA guideline for the management of ST-elevation myocardial infarction. J Am Coll Cardiol 2016; 67: 1235-50.

2. Levine GN, Bates ER, Bittl JA, et al. 2016 ACC/AHA Guideline Focused Update on Duration of Dual Antiplatelet Therapy in $\mathrm{Pa}$ tients With Coronary Artery Disease: A Report of the American College of Cardiology/American Heart Association Task Force on Clinical Practice Guidelines: An Update of the 2011 ACCF/AHA/ SCAI Guideline for Percutaneous Coronary Intervention, 2011 ACCF/AHA Guideline for Coronary Artery Bypass Graft Surgery, 2012 ACC/AHA/ACP/AATS/PCNA/SCAI/STS Guideline for the Diagnosis and Management of Patients With Stable Ischemic Heart Disease, 2013 ACCF/AHA Guideline for the Management of ST-Elevation Myocardial Infarction, 2014 AHA/ACC Guideline for the Management of Patients With Non-ST-Elevation Acute Coronary Syndromes, and 2014 ACC/AHA Guideline on Perioperative Cardiovascular Evaluation and Management of Patients Undergoing Noncardiac Surgery. Circulation 2016; 134: e123-55.

3. Sadjadieh G, Engstrøm T, Høfsten DE, et al. Bleeding events after ST-segment elevation myocardial infarction in patients randomized to an all-comer clinical trial compared with unselected patients. Am J Cardiol 2018; 122: 1287-96.

4. Liu R, Zheng W, Zhao G, et al. Predictive validity of CRUSADE, ACTION and ACUITY-HORIZONS bleeding risk scores in chinese patients with ST-segment elevation myocardial infarction. Circ J 2018; 82: 791-97.

5. Kawashima H, Gao C, Takahashi K, et al. Comparative assessment of predictive performance of PRECISE-DAPT, CRUSADE, and ACUITY scores in risk stratifying 30-day bleeding events. Thromb Haemost 2020; 120: 1087-95.

6. Ranucci M, Castelvecchio S, Menicanti L, et al. Risk of assessing mortality risk in elective cardiac operations: age, creatinine, ejection fraction, and the law of parsimony. Circulation 2009; 119: 3053-61.

7. Dziewierz A, Siudak Z, Rakowski T, et al. The ACEF (age, creatinine, ejection fraction) score predicts ischemic and bleeding outcomes of patients with acute coronary syndromes treated conservatively. Adv Interv Cardiol 2017; 13: 160-4.

8. Dannenberg L, Wolff G, Naguib D, et al. Safety and efficacy of tirofiban in STEMI-patients. Int J Cardiol 2019; 274: 35-9.

9. Huynh T, Piazza N, DiBattiste PM, et al. Analysis of bleeding complications associated with glycoprotein IIb/IIla receptors blockade in patients with high-risk acute coronary syndromes: insights from the PRISM-PLUS study. Int J Cardiol 2005; 100: 73-8.

10. Effects of platelet glycoprotein IIb/llla blockade with tirofiban on adverse cardiac events in patients with unstable angina or acute myocardial infarction undergoing coronary angioplasty. The RESTORE Investigators. Randomized Efficacy Study of Tirofiban for Outcomes and REstenosis. Circulation 1997; 96: 1445-53.

11. Blanc B, Finch CA, Hallberg L, et al. Nutritional anaemias. Report of a WHO Scientific Group: WHO Tech Rep Ser 1968; 1-40.

12. Mehran R, Rao SV, Bhatt DL, et al. Standardized bleeding definitions for cardiovascular clinical trials: a consensus report from the Bleeding Academic Research Consortium. Circulation 2011; 123: 2736-47.

13. Ueki Y, Bär S, Losdat S, et al. Validation of the Academic Research Consortium for High Bleeding Risk (ARC-HBR) criteria in patients undergoing percutaneous coronary intervention and comparison with contemporary bleeding risk scores. Eurolntervention 2020; 16: 371-9.

14. Rubboli A, Patti G. What is the role for glycoprotein IIb/IIla inhibitor use in the catheterization laboratory in the current era? Curr Vasc Pharmacol 2018; 16: 451-8.

15. Sørensen R, Hansen ML, Abildstrom SZ, et al. Risk of bleeding in patients with acute myocardial infarction treated with different combinations of aspirin, clopidogrel, and vitamin $\mathrm{K}$ antagonists in Denmark: a retrospective analysis of nationwide registry data. Lancet 2009; 374: 1967-74.

16. Huynh T, Piazza N, DiBattiste PM, et al. Analysis of bleeding complications associated with glycoprotein Ilb/Illa receptors blockade in patients with high-risk acute coronary syndromes: insights from the PRISM-PLUS study. Int I Cardiol 2005; 100: 73-8.

17. Yan Z, Zhou Y, Zhao Y, et al. Efficacy and safety of tirofiban in high-risk patients with non-ST-segment elevation acute coronary syndromes. Clin Cardiol 2009; 32: E40-4.

18. Brouse SD, Wiesehan VG. Evaluation of bleeding complications associated with glycoprotein IIb/IIla inhibitors. Ann Pharmacother 2004; 38: 1783-8.

19. Lipinski MJ, Lee RC, Gaglia MA Jr, et al. Comparison of heparin, bivalirudin, and different glycoprotein Ilb/Illa inhibitor regimens for anticoagulation during percutaneous coronary intervention: a network meta-analysis. Cardiovasc Revasc Med 2016; 17: 535-45.

20. McKay RG, Boden WE. Small peptide GP IIb/Illa receptor inhibitors as upstream therapy in non-ST-segment elevation acute 
coronary syndromes: results of the PURSUIT, PRISM, PRISMPLUS, TACTICS, and PARAGON trials. Curr Opin Cardiol 2001; 16: 364-9.

21. Tcheng JE. Clinical challenges of platelet glycoprotein IIb/IIla receptor inhibitor therapy: bleeding, reversal, thrombocytopenia, and retreatment. Am Heart J 2000; 139: S38-45.

22. Urban P, Mehran R, Colleran R, et al. Defining high bleeding risk in patients undergoing percutaneous coronary intervention: a consensus document from the Academic Research Consortium for High Bleeding Risk. Eur Heart J 2019; 40: 2632-53.

23. Steg PG, Huber K, Andreotti F, et al. Bleeding in acute coronary syndromes and percutaneous coronary interventions: position paper by the Working Group on Thrombosis of the European Society of Cardiology. Eur Heart J 2011; 32: 1854-64.

24. Ismail N, Jordan KP, Rao S, et al. Incidence and prognostic impact of post discharge bleeding post acute coronary syndrome within an outpatient setting: a systematic review. BMJ Open 2019; 9: e023337.

25. Darmon A, Ducrocq G. Ischaemic and bleeding risk assessment after myocardial infarction: combination is the key. Heart 2019; 105: 1138-9.

26. lijima R, Nagashima Y, Sato K, et al. SYNTAX score predicts major bleeding following drug-eluting stent implantation in an all-comers population. Rev Esp Cardiol 2015; 68: 54-62.

27. Hara H, Kogame N, Takahashi K, et al. GLOBAL LEADERS Trial Investigators. Usefulness of the updated logistic clinical SYNTAX score after percutaneous coronary intervention in patients with prior coronary artery bypass graft surgery: insights from the GLOBAL LEADERS trial. Catheter Cardiovasc Interv 2020; 96: E516-26.

28. Stähli BE, Wischnewsky MB, Jakob P, et al. Predictive value of the age, creatinine, and ejection fraction (ACEF) score in patients with acute coronary syndromes. Int J Cardiol 2018; 270: 7-13.

29. Chichareon P, Modolo R, van Klaveren D, et al. Predictive ability of ACEF and ACEF II score in patients undergoing percutaneous coronary intervention in the GLOBAL LEADERS study. Int J Cardiol 2019; 286: 43-50.

30. Chen $\mathrm{H}, \mathrm{Yu} \mathrm{X}$, Kong $\mathrm{X}$, et al. Predictive value of ACEF score for clinical prognosis of elderly patients with ST-segment elevation myocardial infarction after percutaneous coronary intervention. Ann Palliat Med 2021; 10: 1380-7.

31. Reindl M, Reinstadler SJ, Tiller C, et al. ACEF score adapted to ST-elevation myocardial infarction patients: the ACEF-STEMI score. Int J Cardiol 2018; 264: 18-24.

32. Kristić I, Crnčević N, Runjić F, et al. ACEF performed better than other risk scores in non-ST-elevation acute coronary syndrome during long term follow-up. BMC Cardiovasc Disord 2021; 21: 70.

33. Stucchi M, Cantoni S, Piccinelli E, et al. Anemia and acute coronary syndrome: current perspectives. Vasc Health Risk Manag 2018; 14: 109-18.

34. Vrsalovic M, Pintaric H, Babic Z, et al. Impact of admission anemia, C-reactive protein and mean platelet volume on short term mortality in patients with acute ST-elevation myocardial infarction treated with primary angioplasty. Clin Biochem 2012; 45: 1506-9.

35. Moghaddam N, Wong GC, Cairns JA, et al. Association of anemia with outcomes among ST-segment-elevation myocardial infarction patients receiving primary percutaneous coronary intervention. Circ Cardiovasc Interv 2018; 11: e007175. 